Research Article

\title{
Evaluation of Cell Formation Algorithms and Implementation of MOD-SLC Algorithm as An effective Cellular Manufacturing System in a Manufacturing Industry
}

\author{
V. Satheeshkumar ${ }^{\dot{A} *}$, K. Karthikeyan ${ }^{\dot{A}}$, C.J. Thomas Renald ${ }^{\dot{B}}$, V. Jagadeesh $^{\dot{C}}$, R. Silambarasan ${ }^{\dot{D}}$ and C. Bhagyanathan $^{\dot{A}}$ \\ ${ }^{\AA}$ Department of Mechnaical Engineering, Sri Ramakrishna Engineering College, Coimbatore, Tamilnadu, India \\ ${ }^{b}$ Department of Aeronautical Engineering, Sri Ramakrishna Engineering College, Coimbatore, Tamilnadu, India \\ ${ }^{\mathrm{C}}$ Department of Business and Administration, Kalaignar Karunanidhi Institute of Technology, Coimbatore, Tamilnadu, India \\ ${ }^{\mathrm{D}}$ Department of Business and Administration, Karpagam University, Coimbatore, Tamilnadu, India
}

Accepted 10 January 2014, Available online 01 February 2014, Special Issue-2, (February 2014)

\begin{abstract}
Benefits of cellular manufacturing system depend on major factors namely the design of machine cells and part family, setup time and method of operation. Cellular Manufacturing System (CMS) become a failure when these two factors are not properly employed. This work incorporates five array-based clustering algorithms namely Single linkage clustering method (SLC), Modified-Single Linkage Clustering method (MOD-SLC), Direct Clustering Analysis (DCA), Rank Order Clustering (ROC) and Rank Order Clustering-2 (ROC-2) for analyzing real time manufacturing delay with manufacturing cell formation. In the present study, Modified-Single Linkage Clustering (MOD-SLC) method outperforms the other four methods, regardless of the measure used, irrespective of any additional prevalence of exceptional elements in the data set. The results are validated with real time manufacturing systems data.
\end{abstract}

Keywords: Part family; Machine cell; Setup time; Cell formation Algorithms; Performance measures.

\section{Introduction}

Cell formation involves the process of analyzing parts or machine populations, grouping those parts with similar design features or manufacturing routings into families and forming the corresponding machines into cells. There has been extensive work done in this area and numerous clustering algorithms have been applied or developed in practice. The Rank Order Clustering (ROC), enhanced rank order clustering (ROC2), DCA are among the popular cluster analysis based MCF problem solution methods (King, 1980, 1982, Chan and Milner, 1982). Different types array-based methods and hierarchical methods were developed and proposed in the earlier periods (King, 1980, 1982, Gongaware and Ham, 1991, Mosier and Taube, 1985(a, b), Gupta and Seifoddini, 1990, Seifoddini, 1989(a, b), Islam and Sarker, 2000, Yasuda and Yin, 2001, Dimopoulos and Mort, 2001). These methods have the disadvantage of not forming product and machine cells simultaneously; so additional methods need to be employed to complete the design of the system. Grouping Efficiency (GE) is one of the crucial parameter to be considered in cell formation systems (Chandrasekharan and Rajagopalan, 1986(a, b)). Graph decomposition problem is to determine machine cells and part families for

*Corresponding author: V. Satheeshkumar

DOI: http://dx.doi.org/10.14741/ijcet/spl.2.2014.33 a fixed number of groups and with bounds on cell size (Kumar et al., 1986, Vannelli and Kumar, 1986).

Kumar and Vannelli et al., (1987) developed a similar procedure for determining parts to be subcontracted in order to obtain a perfect block diagonal structure. These methods are found to be depending on the initial pivot element choice. Co et al. (1988) developed a three-stage procedure to form cells and solved a 3-assignment problem to assign jobs to machines. Seifoddini (1989a) compared the SLC and ALC methods. Gunasingh et al. (1989) formulated an integer-programming problem to group machines and products for cellular manufacturing systems. Chandrasekharan et al. (1989) analyzed the performance of the grouping efficiency in evaluating the solution qualities of a set of well-structured and illstructured problems. The deficiency of the grouping efficiency has been investigated by Kumar et al. (1990). A comprehensive comparison of three array-based clustering techniques is given. The quality of the solution given by these methods depends on the initial configuration of the zero-one matrix Chu and Tsai (1990). Srinivasan (1990) modeled the problem as an assignment problem to obtain product and machine cells. Vohra et al. (1990) suggested a network based approach to solve the grouping problem and used a modified form of the Gomory-Hu algorithm to decompose the part-machine graph. Askin et al. (1991) proposed a Hamiltonian-path algorithm for the grouping problem. David et al. (1998)

183 | International Conference on Advances in Mechanical Sciences 2014 
proposed an effective algorithm to identify part-families and bottleneck-parts, given machine groupings. Prabbahakaran et al. (2002) addressed on an application of the maximal Spanning Tree approach for machine cell formation. Hassan et al. (2003) used the four published performance measures in evaluating and comparing a Modified Single Linkage Clustering heuristic (MOD-SLC) against the three well-established machine cell formation methods. Chang et al. (2006) proposed a multi-functional MP model that incorporates the merits of related $\mathrm{CF}$ models based on the systematic study of MP models. Murugan et al. (2007) implemented cellular manufacturing system using cell formation algorithms namely ROC, ROC-2 and DCA and validated the better performance of DCA. Alhourani et al. (2007) proposed a new ordinal production data similarity coefficient based on the sequence of operations and the batch size of the parts.

While conducting the detailed literature survey, it has been found that many cell formation methods have been used to reduce the percentage of exceptional elements $(\mathrm{PE})$ and to increase the Grouping Efficiency (GE). The result of the literature survey indicates the absence of an analysis on cell formation methods using the real time data to predict the performance.

In the present work, comparison has been made on the following five machine component cell formation algorithms namely,

1. Single Linkage Clustering method (SLC)

2. Modified-Single Linkage Clustering method (MODSLC)

3. Rank Order Clustering method (ROC)

4. Rank Order Clustering-2 method (ROC-2)

5. Direct Clustering Analysis (DCA)

The above algorithms use the initial Machine Component Incidence Matrix (MCIM) as input to solve the problem.

\section{Problem Definition}

The main problem faced by the company is that their existing layout is used to manufacture the parts for all types of the pumps such as mono-block, jet pump and submersible pump etc, which causes a congested flow and bottlenecks. The company wanted to manufacture the submersible pumps in a separate plant. A leading pump manufacturing company decided to design a cellular layout for their submersible pumps division,

- To calculate the machine requirements for the new layout.

- To develop programs for each type of cell formation algorithms to compute the results automatically.

- To compare the various cell formation algorithms and to find the most suitable algorithm for the given problem.

- To design a cellular layout from the best result obtained among the best suited algorithm.

- To compare the performance of the cellular layout with the traditional layout in terms of productivity improvement, reduction in material handling distance and reduction in floor space requirements.

\section{Case Study}

The present case study data are collected from a leading submersible pump; domestic and agricultural pump manufacturing company, producing varieties of components. The submersible pump under consideration has two main sub-assemblies namely the motor and the pump. The pump has 30 parts and the motor has 33 parts, out of 63 parts, only 8 main parts are manufactured in house and others are purchased from other suppliers. We have considered only 8 components and 7 machines. The components sequence and their processing times are given in the Table 1. From the data collected, Machine Component Incidence Matrix (MCIM) is prepared and shown below.

Table 1 Machine component incidence matrix (MCIM)

\begin{tabular}{lllllllll}
\hline \multicolumn{1}{c}{ Parts } & & & & & & \\
\hline M/C & $\mathbf{1}$ & $\mathbf{2}$ & $\mathbf{3}$ & $\mathbf{4}$ & $\mathbf{5}$ & $\mathbf{6}$ & $\mathbf{7}$ & $\mathbf{8}$ \\
$\mathbf{1}$ & & 1 & & 1 & & & & \\
$\mathbf{2}$ & 1 & 1 & & & & 1 & 1 & 1 \\
$\mathbf{3}$ & & & 1 & & & 1 & & 1 \\
$\mathbf{4}$ & & & & 1 & & & 1 & \\
$\mathbf{5}$ & 1 & & 1 & & 1 & 1 & & 1 \\
$\mathbf{6}$ & & & & 1 & & & 1 & \\
$\mathbf{7}$ & 1 & 1 & & & & 1 & 1 & 1 \\
\hline
\end{tabular}

\section{Methodology}

Various algorithms used to solve the initial Machine Component Incidence Matrix (MCIM) are given below:

\subsection{Modified-Single Linkage Clustering(MOD-SLC)}

Baroni et al. (1976) defined a set of properties of similarity coefficients and applied these properties to the several similarity coefficients. There does not exist any similarity coefficient which follows all the properties defined. Islam et al. (2000) modified the properties proposed by Baroni et al. (1976) and stated them as follows $\left(S_{i j}\right.$ is the machine $i$ and machine $\mathrm{j}$ similarity coefficient):

No mismatch, $\quad S_{i j} \rightarrow 1$ for $X_{i}=X_{j}=0$.

Minimum matches, $S_{i j} \rightarrow 0$ for $X_{i j}, Y_{i j} \rightarrow 0$.

No match, $\quad S_{i j} \rightarrow 0$ for $X_{i j},=0$.

Complete match, $S_{i j}=1$ for $X_{i j}=$ number of parts.

Maximum matches, $S_{i j} \rightarrow 1$ for $X_{i j}+Y_{i j} \rightarrow$ number of parts.

The similarity measure developed by Baroni et al. (1976) BUB measure - has conformed to the five properties. This similarity coefficient has superior properties of distribution compared to other coefficients because the distribution of its values is more normal and continuous (1996). The BUB similarity coefficient is defined as follows:

$S_{i j}=\frac{X_{i j}+\sqrt{X_{i j} Y_{i j}}}{X_{i}+X_{j}+X_{i j}+\sqrt{X_{i j}} Y_{i j}}$ 
where $\mathrm{SB}_{\mathrm{ij}}=\mathrm{BUB}$ similarity between machine $\mathrm{i}$ and machine $\mathrm{j}, 0 \leq \mathrm{SB}_{\mathrm{ij}} \leq 1$. In order to justify the application of non- Jaccardian similarity coefficients to the MCF problem, Islam et al. (2000) used properties 2 and 5 to conclude that both matches $\left(\mathrm{X}_{\mathrm{ij}}\right)$ and misses $\left(\mathrm{Y}_{\mathrm{ij}}\right)$ must be included in the numerator of the defining similarity coefficient. To satisfy properties 2,3 , 4, and 5, the product $\mathrm{X}_{\mathrm{ij}} \mathrm{Y}_{\mathrm{ij}}$ is considered in addition to $\mathrm{X}_{\mathrm{ij}}$ in the numerator. The square root is used to maintain the order consistency (Baroni and Buser, 1976). When there are no misses $\left(\mathrm{Y}_{\mathrm{ij}}=\right.$ 0 ), BUB measure is reduced to Jaccard's measure which is the ratio of the number of parts processed by both machines to the total number of parts processed by both or one of the machines. If $\left(\mathrm{Y}_{\mathrm{ij}}\right) \mathrm{A}$ the BUB coefficient value increases to reflect the real similarity of machine/part pairs. Islam et al. (2000) modified BUB measure by adding the number of misses $\left(\mathrm{Y}_{\mathrm{ij}}\right)$ to the denominator and called it 'relative matching measure'. The Jaccard measure has conformed to only three out of the same five properties namely, properties 1, 3 and 4. The Jaccard similarity measure has several additional limitations which have been discussed for years by a number of researchers Shafer et al. (1993a): The first limitation occurs when there is a high similarity between two machines and the Jaccard measure does not detect it.

\subsection{Rank Order Clustering -2 (ROC-2)}

In ROC-2 the rows and columns are rearranged to form the clustered matrix.

\section{Algorithm}

Step 0: Input: Machine-component incidence matrix (MCIM) formed from the operation sequence of each part.

Step 1: Start from the last column, move the rows with positive entries to the top of the matrix.

Step 2: Repeat step1 for all the columns.

Step 3: Start from the last row, move the columns with positive entries to the left of

the matrix.

Step 4: Repeat step 3 for all rows.

Step 5: Compare the matrix with the previous result. If the matrices are different go to step 1 otherwise to step 6 .

Step 6: Print the final machine-component incidence matrix.

\subsection{Direct Clustering Analysis (DCA)}

In the DCA algorithm the initial matrix is rearranged according to the row and column assignments. The rows and columns are rearranged to form the clustered Machine Component Incidence Matrix.

Algorithm

Step 0: Input: Machine Component Incidence Matrix (MCIM) formed from the operation sequence of each part.

Step 1: The row and column ranks are found by adding their corresponding positive entries.

Step 2: The matrix is rearranged according to the ranks.

Step 3: Start from the first row, move the columns with positive entries to the left of the matrix.
Step 4: Repeat the step 3 for all the rows.

Step 5: Start from the first column, move the rows with positive entries to the top.

Step 6: Repeat the step 5 for all the columns.

Step 7: Compare the matrix with the previous result. If the matrices are different go to step 3 otherwise go to step 8 .

Step 8: Print the final machine component incidence matrix.

\subsection{Single Linkage Clustering (SLC)}

It is a hierarchical machine grouping method known as Single-Linkage Cluster analysis using similarity coefficients between machines. The similarity coefficient between two machines is defined as the ratio of the number of parts visiting both machines and the number of parts visiting one of the two machines:

$S_{i j}=\frac{\sum_{k=1}^{N} X_{i j k}}{\sum_{k=1}^{N}\left(Y_{i k}+Z_{j k}-X_{i j k}\right)}$

where $\mathrm{X}_{\mathrm{ijk}}=$ operation on part $\mathrm{k}$ performed both on machine $\mathrm{i}$ and $\mathrm{j}$,

$\mathrm{Y}_{\mathrm{ik}}=$ operation on part $\mathrm{k}$ performed on machine $\mathrm{i}$,

$\mathrm{Z}_{\mathrm{jk}}=$ operation on part $\mathrm{k}$ performed on machine $\mathrm{j}$.

\section{Algorithm}

Step 1: Compute similarity coefficients for all possible pairs of machines.

Step 2: Select the two most similar machines to form the first machine cell.

Step 3: Lower the similarity level (threshold) and form new machine cells by including all the machines with similarity coefficients not less than the threshold value.

Step 4: Continue step 3 until all machines are grouped into a single cell.

\subsection{Rank Order Clustering (ROC)}

In ROC the rows and columns are rearranged to form the clustered matrix.

\section{Algorithm}

Step 1: For row $m=1,2, \ldots \ldots, M$, compute the decimal equivalent $\mathrm{cm}$ by reading the entries as binary words:

i.e. $\mathrm{c}_{\mathrm{m}}=\sum_{p=1}^{P} 2^{\mathrm{P}-\mathrm{p}} \mathrm{a}_{\mathrm{pm}} \quad ;\left(\mathrm{a}_{\mathrm{pm}}=0\right.$ or 1$)$

Reorder the rows in decreasing $\mathrm{c}_{\mathrm{m}}$. In the case of a tie, keep the original order.

Step 2: For column $\mathrm{p}=1,2, \ldots \ldots, \mathrm{P}$, compute the decimal equivalent $\mathrm{p} \mathrm{r}_{\mathrm{p}}$, by reading the entries as binary words:

i.e. $\mathrm{r}_{\mathrm{p}}=\sum_{m=1}^{M} 2^{\mathrm{M}-\mathrm{m}} \mathrm{a}_{\mathrm{pm}} ;\left(\mathrm{a}_{\mathrm{pm}}=0\right.$ or 1$)$

Reorder the columns in decreasing $r_{p}$. In the case of a tie, keep the original order. 
Step 3: If the new machine-part matrix is unchanged, then stop, else go to step 1 .

\section{Program Developed}

Programs were developed for SLC, ROC, MOD-SLC, ROC-2 and DCA algorithms using the $\mathrm{C}++$ language. These programs automatically generate the result when the initial matrix is given to it.

\subsection{Need for the program}

The algorithms may require many iterations until the results merge, so it is tedious to do calculations manually, which can consume time and also the chances for the errors are more.

\subsection{About the program}

Three programs were developed for SLC, ROC, MODSLC, ROC-2 and DCA. The program takes the MCIM as the problem, which is stored in a text file (INPUT.TXT) as tab delimited entries. After the computation the results are written to another text file (OUTPUT.TXT).

\subsection{Evaluation parameter}

The four main parameters were used to evaluate the cells formed are

\subsubsection{Exceptional Elements (e)}

The number of off-diagonal positive entries (exceptional elements) in the final machine part incidence matrix can measure the quality of the cluster formation method. PE can be computed as

$P E=e_{0}$

where $\mathrm{e}_{0}$ is the number of exceptional elements or the offdiagonal positive entries.

\subsubsection{Voids (v)}

Voids indicate that all parts assigned to the cell do not require a machine assigned to a cell. Leads to large, inefficient cells and can potentially contribute to low utilizations.

\subsubsection{Efficiency $(\eta)$}

GE is an aggregate measure that takes both the number of exceptional elements and the machine utilization into consideration. A convex combination of both terms is considered to reveal the relative importance of each term. As a rule as higher the GE the better the clustering results. Grouping Efficiency,

$\eta=w \eta_{1}+(1-w) \eta_{2}$

$\eta_{1}=\frac{\mathrm{o}-\mathrm{e}}{\mathrm{o}-\mathrm{e}+\mathrm{v}}$

$\eta_{2}=\frac{M P-o-v}{M P-o+e-v}$ where $\mathrm{w}-$ Weighing factor

o - Number of 1's in the matrix

e - Number of exceptional elements

$\mathrm{v} \quad$ - Number of voids

M - Number of machines

$\mathrm{P} \quad$ - Number of parts

$\eta=1$ implies no voids and no exceptional elements (perfect clustering)

\subsubsection{Efficacy $(\tau)$}

GC overcomes the problem of selecting w and the limiting range of GE. GC has the requisite properties like nonnegativity, 0-1 ranges and is not affected by the size of the MCIM i.e., the number of parts or machine is not considered.

Grouping Efficacy:

$\tau=\frac{\mathrm{o}-\mathrm{e}}{\mathrm{o}+\mathrm{v}}$

where $o-$ Number of 1 's in the matrix

$\mathrm{e}-$ Number of exceptional elements

$\mathrm{v}-$ Number of voids.

$\tau=1$ implies no voids and no exceptional elements (perfect clustering)

$\tau=0$ implies all 1's are outside the diagonal blocks.

\section{Results and discussion}

Table 2 Final matrix after applying ROC-2 algorithm

\begin{tabular}{|c|c|c|c|c|c|c|c|c|}
\hline \multirow{2}{*}{$\mathrm{M} / \mathrm{c}$} & \multicolumn{8}{|c|}{ Parts } \\
\hline & 6 & 8 & $\mathbf{1}$ & 7 & 2 & 3 & 5 & 4 \\
\hline 2 & 1 & 1 & 1 & 1 & 1 & & & \\
\hline 7 & 1 & 1 & 1 & 1 & 1 & & & \\
\hline 5 & 1 & 1 & 1 & & & 1 & 1 & \\
\hline 3 & 1 & 1 & & & & 1 & & \\
\hline 1 & & & & 1 & 1 & & & 1 \\
\hline 4 & & & & 1 & & & & 1 \\
\hline 6 & & & & 1 & & & & 1 \\
\hline
\end{tabular}

Table 3 Final matrix after applying DCA algorithm

\begin{tabular}{|c|c|c|c|c|c|c|c|c|}
\hline & \multicolumn{8}{|c|}{ Parts } \\
\hline $\mathrm{M} / \mathrm{c}$ & 5 & 3 & 4 & 2 & 1 & 8 & 7 & 6 \\
\hline 7 & & & & 1 & 1 & 1 & 1 & 1 \\
\hline 5 & 1 & 1 & & & 1 & 1 & & 1 \\
\hline 2 & & & & 1 & 1 & 1 & 1 & 1 \\
\hline 3 & & 1 & & & & 1 & & 1 \\
\hline 6 & & & 1 & & & & 1 & \\
\hline 4 & & & 1 & & & & 1 & \\
\hline 1 & & & 1 & 1 & & & & \\
\hline
\end{tabular}

Table 4 Similarity coefficients after applying MOD-SLC algorithm

\begin{tabular}{|c|c|c|c|c|c|c|c|}
\hline \multirow[b]{2}{*}{$\mathbf{M} / \mathbf{c}$} & \multicolumn{6}{|c|}{$\mathbf{M} / \mathbf{c}$} & \multirow[b]{2}{*}{7} \\
\hline & 1 & 2 & 3 & 4 & 5 & 6 & \\
\hline 1 & & 0.50 & & 0.84 & & 0.84 & 0.50 \\
\hline 2 & & & 0.5 & 0.33 & 0.54 & 0.33 & 1 \\
\hline 3 & & & & 0 & 0.75 & 0 & 0.5 \\
\hline 4 & & & & & 0 & 1 & 0.33 \\
\hline 5 & & & & & & 0 & 0.54 \\
\hline 6 & & & & & & & 0.33 \\
\hline 7 & & & & & & & \\
\hline
\end{tabular}




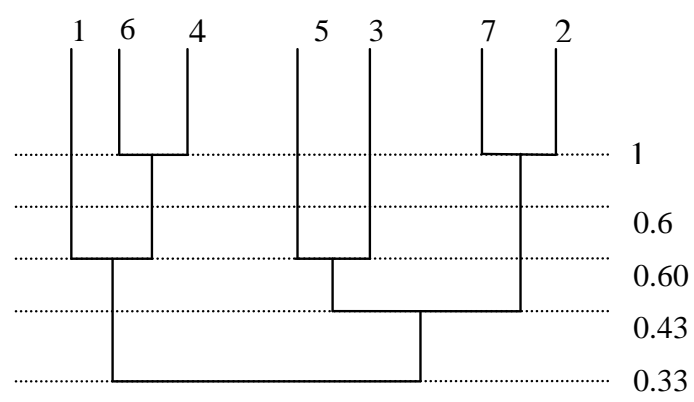

Fig. 1 MOD-SLC Dendogram

Table 6 Similarity matrix of SLC

\begin{tabular}{llllllll}
\hline & $\mathrm{M} / \mathrm{c}$ & & & & & \\
$\mathrm{M} / \mathrm{c}$ & $\mathbf{1}$ & $\mathbf{2}$ & $\mathbf{3}$ & $\mathbf{4}$ & $\mathbf{5}$ & $\mathbf{6}$ & $\mathbf{7}$ \\
\hline $\mathbf{1}$ & & 0.33 & & 0.67 & & 0.67 & 0.33 \\
$\mathbf{2}$ & & & 0.33 & 0.17 & 0.43 & 0.17 & 1.00 \\
$\mathbf{3}$ & & & & & 0.60 & & 0.33 \\
$\mathbf{4}$ & & & & & & 1.00 & 0.17 \\
$\mathbf{5}$ & & & & & & & 0.43 \\
$\mathbf{6}$ & & & & & & & 0.17 \\
$\mathbf{7}$ & & & & & & & \\
\hline
\end{tabular}

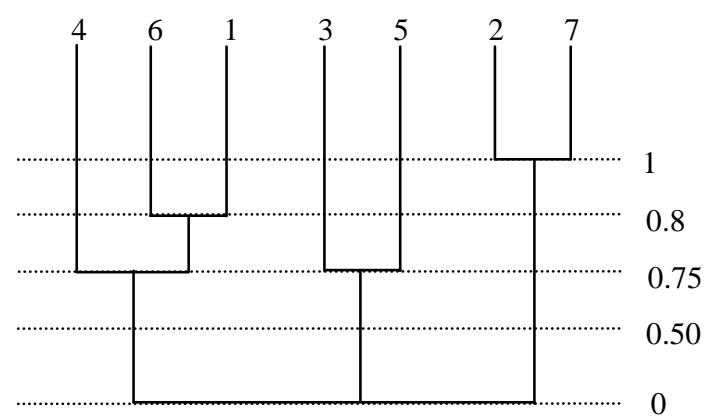

Fig. 2 SLC Dendogram

Table 5 Final matrix after applying MOD-SLC algorithm

\begin{tabular}{lllllllll}
\hline & Parts & & & & & & \\
$\mathbf{M} / \mathbf{c}$ & $\mathbf{4}$ & $\mathbf{7}$ & $\mathbf{1}$ & $\mathbf{2}$ & $\mathbf{8}$ & $\mathbf{5}$ & $\mathbf{6}$ & $\mathbf{3}$ \\
\hline $\mathbf{4}$ & 1 & 1 & & & & & & \\
$\mathbf{6}$ & 1 & 1 & & & & & & \\
$\mathbf{1}$ & 1 & & & 1 & & & & \\
$\mathbf{2}$ & & 1 & 1 & 1 & 1 & & 1 & \\
$\mathbf{7}$ & & 1 & 1 & 1 & 1 & & 1 & 1 \\
$\mathbf{3}$ & & & & & 1 & & 1 & 1 \\
$\mathbf{5}$ & & & 1 & & 1 & 1 & 1 & 1 \\
\hline
\end{tabular}

Table 7 Final matrix of SLC

\begin{tabular}{lcccccccc}
\hline & \multicolumn{2}{c}{ Parts } & & & & & & \\
$\mathbf{M} / \mathbf{C}$ & $\mathbf{4}$ & $\mathbf{7}$ & $\mathbf{1}$ & $\mathbf{2}$ & $\mathbf{3}$ & $\mathbf{5}$ & $\mathbf{6}$ & $\mathbf{8}$ \\
\hline $\mathbf{4}$ & 1 & 1 & & & & & & \\
$\mathbf{6}$ & 1 & 1 & & & & & & \\
$\mathbf{1}$ & 1 & 1 & & 1 & & & & \\
$\mathbf{2}$ & & 1 & 1 & 1 & & & 1 & 1 \\
$\mathbf{7}$ & & 1 & 1 & 1 & & & 1 & 1 \\
$\mathbf{3}$ & & & & & & & & 1 \\
$\mathbf{5}$ & & & & & 1 & & 1 & 1 \\
\end{tabular}

Table 8 Final Matrix of ROC

\begin{tabular}{|c|c|c|c|c|c|c|c|c|}
\hline \multirow[b]{2}{*}{$\mathrm{M} / \mathrm{C}$} & \multicolumn{8}{|c|}{ Parts } \\
\hline & 7 & 4 & 6 & 1 & 8 & 5 & 3 & 2 \\
\hline 4 & & & & 1 & & & 1 & 1 \\
\hline 1 & & 1 & & 1 & & & & \\
\hline 5 & 1 & & 1 & & 1 & 1 & & 1 \\
\hline 6 & & & & 1 & & & 1 & 1 \\
\hline 3 & & & 1 & & & 1 & & 1 \\
\hline 7 & 1 & 1 & & & & 1 & 1 & \\
\hline 2 & 1 & 1 & & & & 1 & 1 & \\
\hline
\end{tabular}

Table 2 shows the final matrix after applying ROC-2 algorithm which results 7 exceptional elements and 5 voids. Table 3 presents the final matrix after applying DCA algorithm which results 7 exceptional elements and 5 voids same like ROC- 2 method for this problem. Table 4 shows the similarity coefficients after applying MOD-SLC algorithm for constructing dendogram that is shown in fig. 1. Table 5 represents the final matrix after applying MODSLC algorithm that results 2 exceptional elements and 3 voids. To the next, Table 6 shows the similarity coefficient matrix after using SLC method for constructing dendogram that is shown in Fig. 2 and Table 7 reveals the final matrix after applying SLC method which results 4 exceptional elements and 5 voids. Table 8 represent the final Matrix after applying ROC method for this problem that results 7 exceptional elements and 6 voids.

rom the results obtained, it is clear that modified-single linkage clustering method gives the better performance for the above problem. The result has 2 exceptional elements, 3 voids, grouping efficiency is $91.33 \%$ and grouping efficacy is $82.14 \%$. Weighing factor was selected as 0.412 , given by Mukhopadhyay et al. (1995). Thus, it was found that MOD-SLC algorithm gives better result than the other two in this case study. The results obtained from the five cell formation algorithms are shown in Table 9 and the comparison of performance measure all methods are shown graphically in Figure 9.

6.1 Graphical results of algorithm Vs. evaluating parameters

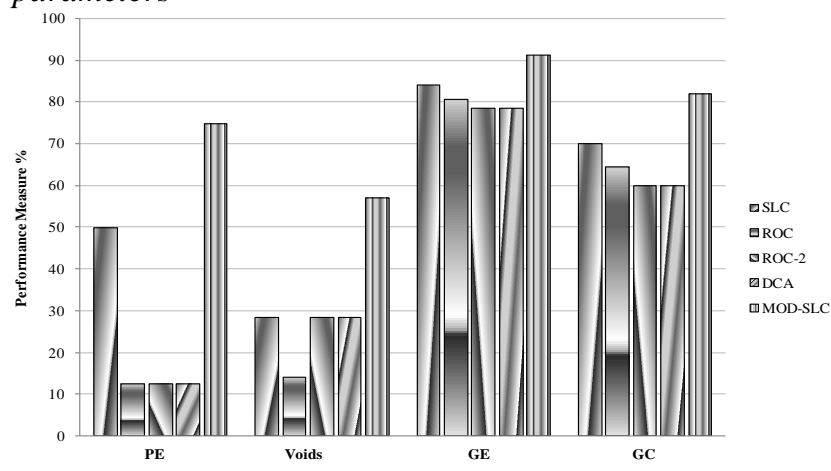

Fig. 3 Overall comparisons of cell formation algorithms and performance measures

187 | International Conference on Advances in Mechanical Sciences 2014 


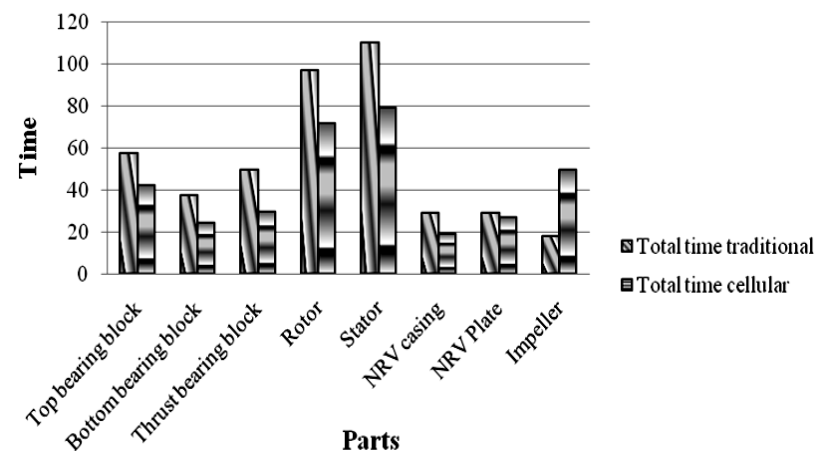

Fig. 4 Total Production Time

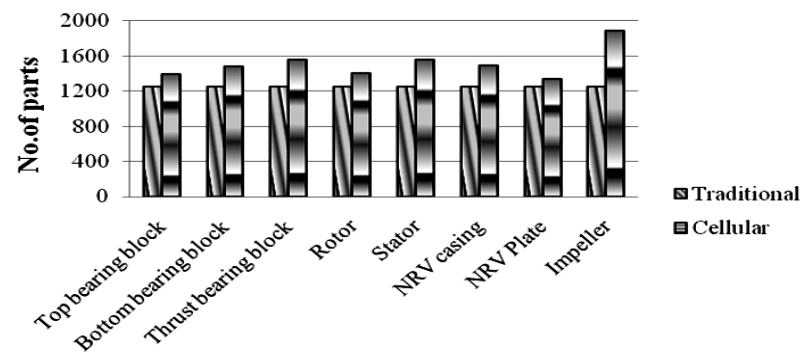

Fig. 5 Productivity

Table 9 Numerical results cell formation algorithms

\begin{tabular}{|c|c|c|c|c|c|}
\hline Algorithms & SLC & ROC & $\begin{array}{l}\text { ROC- } \\
2\end{array}$ & DCA & $\begin{array}{l}\text { MOD } \\
\text {-SLC }\end{array}$ \\
\hline & & & & & \\
\hline PE (Nos.) & 4 & 7 & 7 & 7 & 2 \\
\hline Voids (Nos.) & 5 & 6 & 5 & 5 & 3 \\
\hline GE $\%$ & 84.26 & 80.66 & 79.18 & 79.18 & 91.33 \\
\hline GC $\%$ & 70 & 64.52 & 62.5 & 62.5 & 82.14 \\
\hline
\end{tabular}

Figure 5 shows the overall improved performance of MOD-SLC algorithm than SLC, ROC, ROC-2 and DCA based on all evaluation parameters.

\subsection{Cells formed}

Based on the machine component incidence matrix, the final result obtained from the MOD-SLC algorithm was designed with four cells.

Table 10 Machine group and cell formation

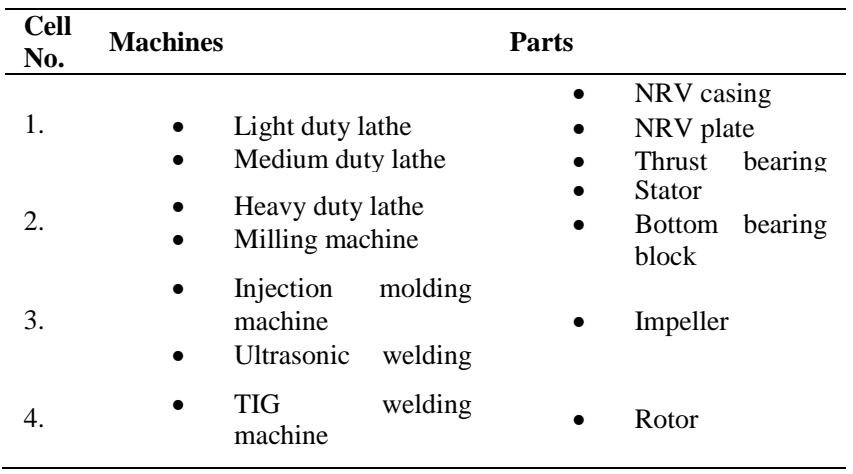

The grouped machines and the relevant part families in each cell are given in Table 10.

\subsection{Evaluation and comparison of other parameters}

Similarly the other parameters such as total production time, productivity and total material handling distance are compared based on the From - To chart shown in Table 11. The modified incidence matrix and peforamnce improvements are shown in Table 11 and Table 12, respectively. Apart from the considered machines, some other supporting machines were also considered while designing cellular layout for the improved operations. Graphical representations of improved results of total production time, productivity and total material handling distance are shown in figures from 4 to 6 .

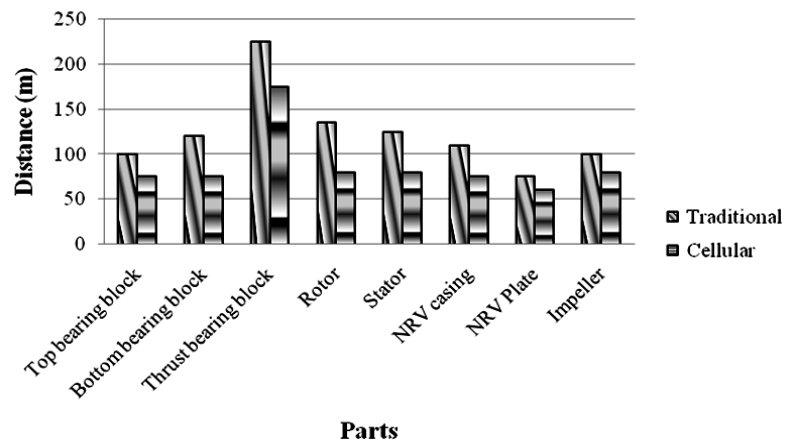

Fig. 6 Total travelling distance

\section{Conclusion}

In this work, the response improvement in the industry on manufacturing of submersible pump by using cellular manufacturing systems has been examined. exceptional elements, voids, group efficiency and group efficacy measures were used to evaluate the five clustering algorithms namely SLC, ROC, ROC-2, DCA, MOD-SLC. MOD-SLC resulted in a smaller number of exceptional elements (2), voids (3) higher grouping efficiency of $\mathbf{9 1 . 3 3 \%}$ and higher grouping efficacy of $\mathbf{8 2 . 1 4 \%}$. The results of clustering indicate that MOD-SLC is more effective than ROC-2 and DCA based on the analysed performance measures. Cellular Layout model has been designed based on the selected MOD-SLC algorithm. The existing conventional system model and the cellular manufacturing system model were compared under different criteria such as productivity and material handling distance. The results from the comparison indicate that the Cellular Manufacturing System can reduce material handling distance by $\mathbf{5 1 . 2 5} \%$ and can improve productivity by $\mathbf{2 9 . 0 4} \%$. This leads to a faster response than the current system. Cellular Manufacturing also increases production accuracy that yields more timely responses and more competitive business ability.

\section{References}

J.R. King, (1980) Machine-component group formation in group technology, OMEGA, vol. 8, pp.193-199, and also 'Machinecomponent grouping in production flow analysis: an approach 
using a rank order clustering algorithm', International Journal of Production Research, vol.18, pp.213-232.

J.R. King and V. Nakornchai, (1980) Machine-component group formation in group technology: Review and extension, International Journal of Production Research, vol.20, pp.117133.

H.M. Chan and D.A. Milner, (1982) Direct clustering algorithm for group formation in cellular manufacture, Journal of Manufacturing Systems, vol.1, pp.65-75.

T.A. Gongaware and I. Ham, (1991) Cluster analysis applications for group technology manufacturing systems, Proceedings: Ninth North American Manufacturing Research Conference, pp.503-508.

C.T. Mosier and L. Taube, (1985a) The facets of group technology and their impacts on implementation - a state of the art survey, Omega, vol.13, no.5, pp.381-391.

C.T. Mosier and L. Taube, (1985b) Weighted similarity measure heuristics for the group technology machine clustering problem, Omega, vol.13, no.6, pp.577-583.

T. Gupta and H. Seifoddini, (1990) Production data based similarity coefficient for machine-component grouping decision in the design of a cellular manufacturing system, International Journal of Production Research, vol.28, no.7, pp.247-269.

H.K. Seifoddini, (1989a) A note on the similarity coefficient method and the problem of improper machine assignment in group technology problem, International Journal of Production Research, vol.27, no.7, pp.1161-1165.

H.K. Seifoddini, (1989b) Duplication process in machine cells formation in group technology, IIE Transactions, vol.21, no.4, pp.382-388.

M. Khan, S. Islam and B. Sarker, (2000) A similarity coefficient measure and machine-parts grouping in cellular manufacturing systems, International Journal of Production Research, vol.38, no.3, pp.699-720.

K. Yasuda and Y. Yin, (2001) A dissimilarity measure for solving the cell formation problem in cellular manufacturing, Computers and Industrial Engineering. vol.39, no.1, pp.1-17.

C. Dimopoulos and N. Mort, (2001) A hierarchical clustering methodology based on genetic programming for the solution of simple cell-formation problems, International Journal of Production Research, vol.39, no.1, pp.1-19.

M.P. Chandrasekharan and R. Rajagopalan, (1986a) An ideal seed non-hierarchical clustering algorithm for cellular manufacturing, International Journal of Production Research,vol.24, No.2, pp.451-464.

M.P. Chandrasekharan and R. Rajagopalan, (1986b) MODROC: an extension of rank order clustering for group technology, International Journal of Production Research, vol.24, No.5, pp.1221-1233.

K.R. Kumar, A. Kusiak and A. Vannelli, (1986) Grouping of parts and components in flexible manufacturing systems, European Journal of Operational Research, vol.24, pp.387397.

Vannelli and K.R. Kumar, (1986) A method for finding minimal bottle-neck cells for grouping part-machine families, International Journal of Production Research, vol.24, No.2, pp.387-400.

K.R. Kumar and A. Vannelli, (1987) Strategic subcontracting for efficient disaggregated manufacturing, International Journal of Production Research, vol.25, No.4, pp.1715-1728.

H.C. Co and A. Araar, (1988) Configuring cellular manufacturing systems, International Journal of Production Research, vol.26, pp.1511-1522.

K.R. Gunasingh and R.S. Lashkari, (1989) The cell formation problem in cellular manufacturing systems - a sequential modeling approaches, Computers and Industrial Engineering, vol.16, No.4, pp.469-476.
M.P. Chandrasekharan and R. Rajagopalan, (1989) Groupability: An analysis of the properties of binary data matrices for group technology, International Journal of Production Research, vol.27, No.6, pp.1035-1052.

C.S. Kumar and M.P. Chandrasekharan, (1990) Grouping efficacy: A quantitative criterion for goodness of block diagonal forms of binary matrices in group technology, International Journal of Production Research, vol.28, No.2, , pp.233-243.

C.H. Chu and M. Tsai, (1900) A comparison of three array-based clustering techniques for manufacturing cell formation, International Journal of Production Research, vol. 28, No. 8, pp.1417-1433.

G. Srinivasan, T.T. Narendran and B. Mahadevan, (1990) An assignment model for the part-families problem in group technology, International Journal of Production Research, vol.28, No.1, pp.145-152.

T. Vohra, D. Chen, J. Chang and H. Chen, (1990) A network approach to cell formation in cellular manufacturing, International Journal of Production Research, vol.28, No.11, pp.2075-2084.

R.G. Askin, S.H. Cresswell, J.B. Goldberg and A.J. Vakharia, (1991) A Hamiltonian path approaches to reordering the partmachine matrix for cellular manufacturing, International Journal of Production Research, vol.29, No.6, pp.1081-1100.

David S. Ang, (1998) Identifications of part families and bottleneck parts in cellular manufacturing, Industrial Management and Data Systems, vol. 98, No.1, pp.3-7.

G. Prabbahakaran, M. Sachithanandam and N. Venkiah, (2002) Application of the Maximal Spanning Tree Approach for Machine Cell Formation, The International Journal of Advanced Manufacturing Technology, vol. 20, No. 7, pp. 503514.

Hassan M. Selim, Reda M.S. Abdel Aal and Araby I. Mahdi, (2003) Formation of machine groups and part families: a modified SLC method and comparative study, Integrated Manufacturing systems. vol.14, no.2, 2003, pp.123-137

Chang-Chun Tsai and Chung-Ying Lee, (2006) Optimization of manufacturing cell formation with a multi-functional mathematical programming model, The International Journal of Advanced Manufacturing Technology, vol.30, No. 3-4, pp. 309-318.

M. Murugan and V. Selladurai, (2007) Optimization and implementation of cellular manufacturing system in a pump industry using three cell formation algorithms. International Journal of Advanced Manufacturing Technology, vol.35, pp.135-149.

Alhourani Farouq and Seifoddini Hamid, (2007) Machine cell formation for production management in cellular manufacturing systems, International Journal of Production Research, vol. 45, No.4, pp. 913-934.

C. Baroni-Urbani and M.W. Buser, (1976) Similarity of binary data, Systematic Zoology, vol.25, pp.251-259.

K.M.S. Islam and B.R. Sarker, (2000) A similarity coefficient measure and machine-parts grouping in cellular manufacturing systems, International Journal of Production Research, vol.38, No.3, pp.699-720.

B.R. Sarker, (1996) The resemblance coefficients in group technology: a survey and comparative study of relational metrics, Computers and Industrial Engineering, vol.30, No.1, pp.103-116.

S.M. Shafer and D.F. Rogers, (1993a) Similarity and distance measures for cellular manufacturing, Part I. A survey, International Journal of Production Research, vol.31, No.5, pp.1131-1142.

S.K. Mukhopadhyay and A. Gopalakrishnan, (1995) A vector analytic (VECAN) method for solving the machine-part 
grouping problem in GT, International Journal of Production Research, vol.33, pp.795-818.

\section{Appendix}

Table 10 From - To chart

\begin{tabular}{|c|c|c|c|c|c|c|c|c|}
\hline & $\begin{array}{l}\frac{\lambda}{2} \\
\stackrel{2}{n}\end{array}$ & 全 & $\overrightarrow{\mathrm{\Sigma}}$ & $\stackrel{5}{3}$ & $\stackrel{U}{O}$ & 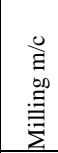 & 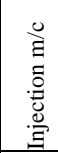 & 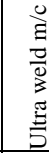 \\
\hline Supply & 0 & 17 & 17 & 50 & 51 & 35 & 40 & 50 \\
\hline HDL & & 0 & 9 & 38 & 35 & 18 & 27 & 35 \\
\hline MDL & & & 0 & 33 & 31 & 17 & 21 & 31 \\
\hline LDL-a & & & & 0 & 16 & 16 & 21 & 16 \\
\hline TIG & & & & & 0 & 18 & 12 & 1 \\
\hline Milling $\mathrm{m} / \mathrm{c}$ & & & & & & 0 & 12 & 17 \\
\hline Injection $\mathrm{m} / \mathrm{c}$ & & & & & & & 0 & 12 \\
\hline Ultra weld $\mathrm{m} / \mathrm{c}$ & & & & & & & & 0 \\
\hline
\end{tabular}

Table 11 Modified machine component incidence Matrix (MCIM)

\begin{tabular}{|c|c|c|c|c|c|c|c|c|c|}
\hline & $\sum_{\frac{3}{2}}^{0}$ & $\begin{array}{l}\tilde{0} \\
\stackrel{0}{0} \\
\underline{\underline{a}}\end{array}$ & $\begin{array}{l}\frac{0}{ \pm} \\
\bar{a} \\
z \\
z \\
z\end{array}$ & 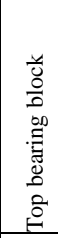 & $\begin{array}{l}\text { 으 } \\
\frac{0}{0} \\
60 \\
0 \\
0 \\
0 \\
0 \\
0 \\
0 \\
\varrho \\
\end{array}$ & $\begin{array}{l}\frac{\overline{0}}{\bar{\Xi}} \\
\text { 节 }\end{array}$ & 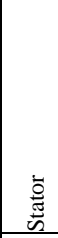 & 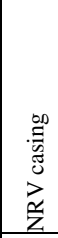 & 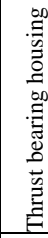 \\
\hline & 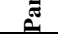 & 4 & 7 & 1 & 2 & 8 & 5 & 6 & 3 \\
\hline $\begin{array}{ll}\text { Injection moulding } \\
\mathrm{m} / \mathrm{c}\end{array}$ & 4 & 1 & 1 & & & & & & \\
\hline Tig welding & 6 & 1 & 1 & & & & & & \\
\hline HDL & 1 & 1 & & & 1 & & & & \\
\hline MDL & 2 & & 1 & 1 & 1 & 1 & & 1 & \\
\hline Ultrasonic weld & 7 & & 1 & 1 & 1 & 1 & & 1 & 1 \\
\hline LDL & 3 & & & & & 1 & & 1 & 1 \\
\hline Milling $\mathrm{m} / \mathrm{c}$ & 5 & & & & 1 & 1 & 1 & 1 & 1 \\
\hline
\end{tabular}

Table 12 Comparison of other parameters (conventional layout Vs. cellular layout)

\begin{tabular}{|c|c|c|c|c|c|c|c|c|c|}
\hline \multicolumn{9}{|c|}{ Comparison of Conventional layout Vs cellular layout } & \multirow{3}{*}{ 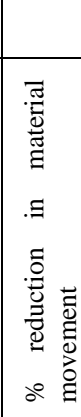 } \\
\hline & \multirow[b]{2}{*}{ 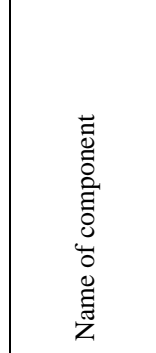 } & \multicolumn{3}{|c|}{$\begin{array}{l}\text { Conventional } \\
\text { Layout }\end{array}$} & \multicolumn{3}{|c|}{ Cellular Layout } & \multirow{2}{*}{ 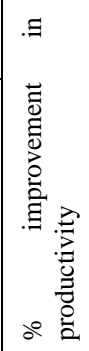 } & \\
\hline 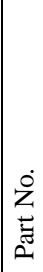 & & 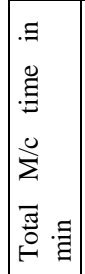 & 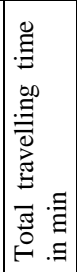 & 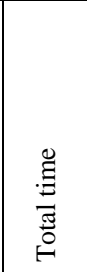 & 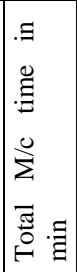 & 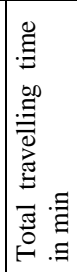 & 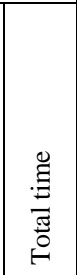 & & \\
\hline 1 & $\begin{array}{l}\text { Top bearing } \\
\text { block }\end{array}$ & 31.37 & 23.4 & 57.907 & 31.37 & 10.9 & 42.27 & 14.78 & 45.78 \\
\hline 2 & $\begin{array}{l}\text { Bottom } \\
\text { bearing } \\
\text { block }\end{array}$ & 16.37 & 19.8 & 37.807 & 16.37 & 8.3 & 24.67 & 24.52 & 41.23 \\
\hline 3 & $\begin{array}{l}\text { Thrust } \\
\text { bearing } \\
\text { block }\end{array}$ & 24.66 & 22.8 & 49.926 & 24.66 & 5.3 & 29.96 & 32.71 & 67.26 \\
\hline 4 & Rotor & 46.2 & 46.5 & 97.32 & 46.2 & 25.7 & 71.9 & 15.67 & 40.41 \\
\hline 5 & Stator & 49 & 56.3 & 110.2 & 49 & 30.28 & 79.28 & 30.25 & 55.86 \\
\hline 6 & NRV casing & 9.66 & 18.8 & 29.426 & 9.66 & 9.45 & 19.11 & 26.8 & 38.54 \\
\hline 7 & NRV Plate & 39.16 & 22.7 & 65.776 & 39.16 & 10.7 & 49.86 & 15.36 & 58.25 \\
\hline \multirow[t]{2}{*}{8} & Impeller & 1.07 & 16.8 & 17.977 & 1.07 & 4.2 & 5.27 & 72.23 & 62.63 \\
\hline & & & & & & & & 29.04 & 51.25 \\
\hline
\end{tabular}

